\title{
Exploring the reflective typology of novice EFL teachers in a Thai university
}

\author{
Thidaporn Jumpakate ${ }^{1}$, Jeffrey Dawala Wilang ${ }^{2}$, Corsica Kong ${ }^{3}$ \\ ${ }^{1,2}$ School of Foreign Languages, Institute of Social Technology, Suranaree University of Technology, Thailand \\ ${ }^{3}$ Independent Researcher, Hong Kong
}

\begin{abstract}
Article Info
\section{Article history:}

Received Oct 14, 2020

Revised Mar 18, 2021

Accepted Apr 16, 2021

\section{Keywords:}

Novice teacher

Professional development

Reflective typology

Reflective writing

ABSTRACT

This paper presents the reflective typology elicited from the three data sets of reflective writings written by novice teachers in Thailand's university context. As part of an action research study to improve a novice teacher's professional development, two teachers volunteered to write reflections for a semester of their assigned courses. Three data sets of reflective writings were submitted at the end of a 16-week semester. Due to our desire to provide a more meaningful interpretation of the reflective writings, grounded theory was used, resulting in two emerging themes-descriptive code, which refers to the description of a specific event in the classroom, and reflective code, which include acts in the classroom where the teacher considered an option and reflected on it. In the typology derived from our study, reflections on teaching, students, and self are common among three data sets. Moreover, the instructional act is a common specific code in both descriptive and reflective codes. The typology can be used to investigate novice teachers ' reflective acts to further their professional development.
\end{abstract}

This is an open access article under the CC BY-SA license.

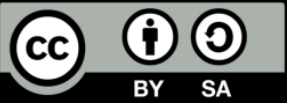

\section{Corresponding Author:}

Thidaporn Jumpakate

School of Foreign Languages, Institute of Social Technology

Suranaree University of Technology

Suranari, Mueang Nakhon Ratchasima District, Nakhon Ratchasima 30000, Thailand

Email: thidaporn.j@sut.ac.th

\section{INTRODUCTION}

Novice teachers, local or foreign, may face challenging and daunting tasks on becoming a teacher per $s e$. Considered the most difficult phase in a teacher's career, their experiences were described as "emotional roller coaster filled with nerves" [1], "sink or swim" [2], and "baptism of fire" [3]. A gap is expected between the novice teacher's professional education and the demand of "real" teaching in the classroom where "they have to teach and they have to learn how to teach" [4]. Novice teachers are described as "surviving in a sensory overload" [5] regarding their relationships with new co-workers, adjusting to the new physical environment, and connecting with new students. For example, they experienced confusion and frustration due to a lack of in-depth contextual knowledge at the workplace.

Understanding teachers through reflective writing is a popular tool in teacher education. Accordingly, the reflective practice involves the teacher's cognitive and affective qualities to have a higher sense of current problematic classroom events to develop a professional self [6]-[8]. Kerka argued that writing a journal is a powerful learning tool mediating between current and new knowledge "breaking habitual ways of thinking, enhancing the development of meta-cognition, increase awareness of tacit knowledge, facilitate selfexploration and work out solutions to problems" [9]. It is a self-development process where teachers analyze and evaluate their own practice, initiate change, and observe or monitor its after effects [10]. 
While many agree that reflective writing is a tool for professional development among pre-service teachers, for instance, identifying their teaching problems and improving their teaching practices [9], [11]-[14], little has been known about what novice teachers reflect in their teaching in higher education, specifically, in Thailand. Once hired in the university, novice teachers are not forced to submit reflective writings. So there remains a lack of knowledge on what novice teachers reflect at the early stage of their teaching career. To this aim, one research question is asked: "What are the practices of novice teachers through their reflective writings?" Such reflective teaching practices will have implications on what and how novice teachers are given help on professional development.

\section{LITERATURE REVIEW}

\subsection{Reflections as a tool for professional development}

Previous studies suggested that reflective writings could help in teacher professional development. Arsal studied the effect of diaries on self-regulation strategies of the pre-service science teachers in Turkey [15]. The participants of the study were 60 pre-service science teachers, 30 of which were in the experimental, and the remaining 30 were in the control group. In this study, the teachers in the experimental group reported the self-regulation strategies they used for daily learning activities by writing the diary-report form for fourteen weeks. The data of the study were collected by the motivated strategies for learning questionnaire. At the end of the study, the intrinsic motivation, task value, metacognition, time management, and strategy usage of the experimental group reported their self-regulation strategies were significantly different from those of the control group.

McDonough investigated the diaries of four novice teachers working on the same language program in terms of various topic headings. He proposed that diary-writing can be a useful tool for both classroom research and personal-professional development. So, diary-writing in an educational context has become a popular technique, with several different application types. It has now been used quite widely in both language teaching and teacher training [16].

For novice English for academic purposes (EAP) teachers in Indonesia, they have to encounter some challenges throughout the first year of teaching, e.g., inadequate preparations for novice teachers before teaching. Hidayati, therefore, explored a sole participant's understandings of and experiences with selfreflection as a form of professional development. The findings showed that the participant used reflective practice and combined theory and practice to construct his professional identity. Henceforth, the participant realized the need for professional development as a novice teacher [17].

In the West, Numrich presented an analysis of 26 diary studies written by novice English as a Second Language (ESL) teachers in the United States. The participants wrote: 1) A personal language learning history; 2) Diary entries during a 10-week teaching semester; and 3) An analysis of their diaries. The data showed that the diaries could reveal novice teachers' teaching behavior, transfer, and rejection of teaching skills used in their own L2 learning, unexpected discoveries about effective teaching, and continued teaching frustrations [18].

Among experienced teachers in Canada, teacher reflection has become an effective tool for promoting teachers' development. Farrell's study sought to investigate in what ways journal writing promoted reflective thinking in one experienced ESL college teacher in Canada over a two-year period of reflection. Results showed that writing a journal could promote constructive behavior changes in both in-class and out-of-class settings [19].

In Thailand, some recent studies pointed out the effectiveness of reflective writing in Thai teachers. Wichadee suggested that personal reflection (diary) is one of the significant ways available to self-monitoring in teaching. She also stated that self-monitoring is seen as a component of teachers' ongoing professional development. To be a successful English as a Foreign Language (EFL) teacher, reflection writing is considered as a tool to enable teachers to see their performance, teaching strategies, and language skills in EFL classrooms [20]. Likewise, Loan studied the effectiveness of the reflective teaching approach. The participants in this study were 48 Thai pre-service teachers in learning to teach EFL writing. They were asked to write their reflections on two guiding questions: 1) what were your strengths and weaknesses about your teaching? and 2) what would you do differently if you were teaching that lesson again? The results illustrated that the pre-service teachers' reflections on their teaching strengths and weaknesses and their plans for reconstructing their teaching revealed some considerations for improvement [21]. Similarly, Suknaisith, Wongwanich, and Piromsombat presented their results on developing teacher performance in educational measurements and evaluation through self- monitoring strategies. It is stated that Thai teachers in the study enlarged knowledge in learning measurements and evaluations, participating in action planning, as well as greater realization and awareness of the importance of learning measurements and evaluations [22]. 
According to previous studies [21], [22], reflective writing could help Thai teachers to reflect on their own strengths and weaknesses. Therefore, the teachers will become life-long learners who are open-minded to improve their teaching performance. Conversely, Wongwanich, Sakolrak and Piromsombat revealed results of their study that Thai teachers trusted and relied on academic scholars from universities rather than reflections from peers and supervisors. Data from interviews also revealed that learning through reflection was an unpleasant experience for Thai teachers. They did not dare to express their opinions or reflections with friends or supervisors. However, self-reflection was not considered and investigated in Wichadee's study. Thus, in this current study, it is worth studying how teachers reflect on their own teaching performance [23].

\subsection{Reflective writing typologies}

Reflective writing is a teacher-centered approach, a bottom-up process where teachers evaluate their own practice. Cohen-Sayag and Fischl argued that reflective writings depict various levels of reflective thinking where teachers may analyse their acts and learn from them. Thus, several reflective frameworks were developed over time [24].

Based on the time frame, Schon proposed reflection-in-action, a classroom event that prompts reflection; and, reflection-on-action, which involves retrospective thinking of a specific classroom event [25]. Farrell added reflection-for-action, which involves reflection of a past event to prepare for the future [26]. Other frameworks identified were Pennington's three developmental stages (procedural, interpersonal, and conceptual stage) [27], Hall's fleeting reflection, committed reflection, and programmatic reflection [28], and Stanley's 5-step framework, including engaging with reflection, thinking reflectively, using reflection, sustaining reflection, and practicing reflection [29].

Jay and Johnson suggested a typology of reflection comprising three aspects: a descriptive reflection of which a problem is described, comparative explanation wherein multiple perspectives are considered, and critical reflection, which involved selecting an action among choices based on how the problem is understood [30]. Yesilbursa outlined 11 reflective sub-categories among Turkish English Language Teaching (ELT) teacher educators, including general reflection, positive reflection, negative reflection, inquiring reflection, reflection on reasons, reflection on solutions, reflection on discoveries, reflection on positive change, reflection on negative change, and commitment to change. She cautioned that the above categories are not hierarchical but rather simultaneous [8].

Among pre-service teachers in Korea, Kim deduced four aspects from their reflective writings on practicum. These are focus on teaching (general teaching issues, teaching demonstration, and classroom observation), focus on self (worth as a teacher, learning teaching skills and feelings), focus on professional issues (fellow intern teachers, institution and school activities, and discussion with mentor teachers), and focus on students or class (student/class behaviour, student/class characteristics, building rapport with students and teaching/consulting specific students). It is possible that specific aspects such as teaching demonstration, fellow interns, and discussion with mentor teachers may not be present in novice teacher's reflective writings. Exploring novice teachers' reflective writings could provide literature on what they reflect in their teaching [31]. In this study. Grounded theory was used as there are several benefits based on studies [32], [33]. Grounded theory's concept was first proposed in the book The Discovery of Grounded Theory as it allows researchers to transform simultaneous data into an explanatory theory [32]. Additionally, Charmanz and Belgrave pointed out that grounded theory helps researchers link subjective experience and social conditions and show how the structure is enacted [33]. Therefore, grounded theory was selected to be used for data analysis in this study.

\section{RESEARCH METHOD}

This action research reported the findings of reflective writings by two volunteer university lecturers who are motivated by their desire to improve their teaching practice. Action research is considered as a "form of self-reflective enquiry undertaken by participants in social situations in order to improve rationality and justice of their own practices, their understanding of these practices, and in which the practices are carried out" [34].

\subsection{Participants of the study}

Two participants of the study were two novice teachers in a top-ranked university in Bangkok. Teacher Bee (a pseudonym), a local, was a fresh MA graduate of Applied Linguistics for English Language Teaching and was assigned to teach foundation English courses to freshmen Engineering students. Another teacher, herein referred to as Fem (a pseudonym), a foreigner, received two masters in Science (non-teaching degrees) and had just earned her teaching English certificate. She was assigned to teach foundation English courses to undergraduate and graduate international programs. Having different educational and personal backgrounds, 
their being novice teacher would shed light on their teaching practices through reflective writings. For the purposes of this study, a novice teacher is someone who has less than five years of teaching experience.

\subsection{Reflective writings}

The data were collected during the first semester of 2018-2019 academic year. Bee and Fem voluntarily wrote weekly reflections. They wrote their teaching experiences for a semester in an open and free format. At the end of the semester, Bee, who taught foundation courses for undergraduate courses, submitted one journal, while Fem provided two journals-one each for her undergraduate and graduate courses. In total, three sets of reflective writings were submitted and analysed. Bee's reflective writings were coded as Set 1, and Fem's reflections in her undergraduate class were coded as Set B, and Set C for her reflective writings in the graduate class. A free format reflective writing was used given the context of the study. Unlike pre-service teachers who need support and practice in writing reflections [35], [36], novice teachers are not bound to do so.

\subsection{Reflective writings analysis procedures}

In the pre-analysis of the qualitative data using "paper and pen" coding, we explored the use of Jay and Johnson's typology [30] and Yesilbura's reflective categories [8] as the main aim of the study is to know the patterns of reflective writing among novice teachers. In the end, due to the complexity of data sets, we used grounded theory to arrive at a tentative set of codes in line with the research question asked. Initial codes were generated by one of the researchers developing patterns and defining its parameters. At the same time, another researcher coded the same data. Afterwards, for inter-rater reliability, the researchers compared and agreed on questionable codes and their parameters.

\section{RESULTS}

Unlike previous typology and reflective writings, results in this study showed comprehensive typology providing general and specific focuses as well as its parameters in understanding the reflective practices of novice teachers in EFL contexts, especially in Thailand. The data analysis process revealed that the three sets of reflections were framed in certain patterns as shown in Table 1 and Table 2.

Table 1 presents 14 descriptive codes and Table 2 shows 10 reflective codes. Patterns in the descriptive code refer to descriptions of the class, instructional act, learning materials, learning environment, students' behaviors and outputs, teacher's background, feelings and outputs, and other issues. On the other hand, patterns in the reflective code refer to the teacher's ability to consider and reflect on the class, instructional act, learning materials, learning environment, students' behaviors and outputs, and teacher's background, feelings, and outputs. In total, 11 reflective acts were coded as shown in Table 2.

We also identified changes in the levels of the novice teachers' reflective thinking. In the example given (Example 1), the teacher described her instructional acts of deciding what to teach and how to teach it. However, it can be noted that her decision to link the vocabulary about food would benefit the students to relate to the topic and be able to do the required task, which is describing the restaurant. Herein, the teacher had shown her awareness of the instructional act she had chosen to help students do the assigned task.

"After that, I decided to teach them how to describe about restaurant so that they can describe about restaurant at the end of the class. I linked to the vocabulary about food which is relevant to appetizer, side dish, main dish, and dessert. By doing so, the students could have background knowledge before studying and doing activities. " (Example 1, Set 1)

"I'm thinking... if they don't enjoy any classroom activities or discussions at all, shall I change my teaching strategy? I may wish to know what ways are the best for them to learn. Do they prefer a non-stop lecture instead of having any classroom activities? " (Example 2, Set 2)

In Example 2, the teacher contemplated on what instructional act is best for the students. Her awareness of what students enjoy or do not enjoy in class made her reflect on her teaching strategy. In addition, in Example 3, the teacher noted that students enjoyed discussing, so she decided to utilize discussion in her next class.

"I think the students enjoyed discussing their own writing as they could know what exactly the mistakes they made when writing. I really should try doing this kind of exercise and discussion again." (Example 3, Set 3) 
Table 1. Descriptive codes and parameters

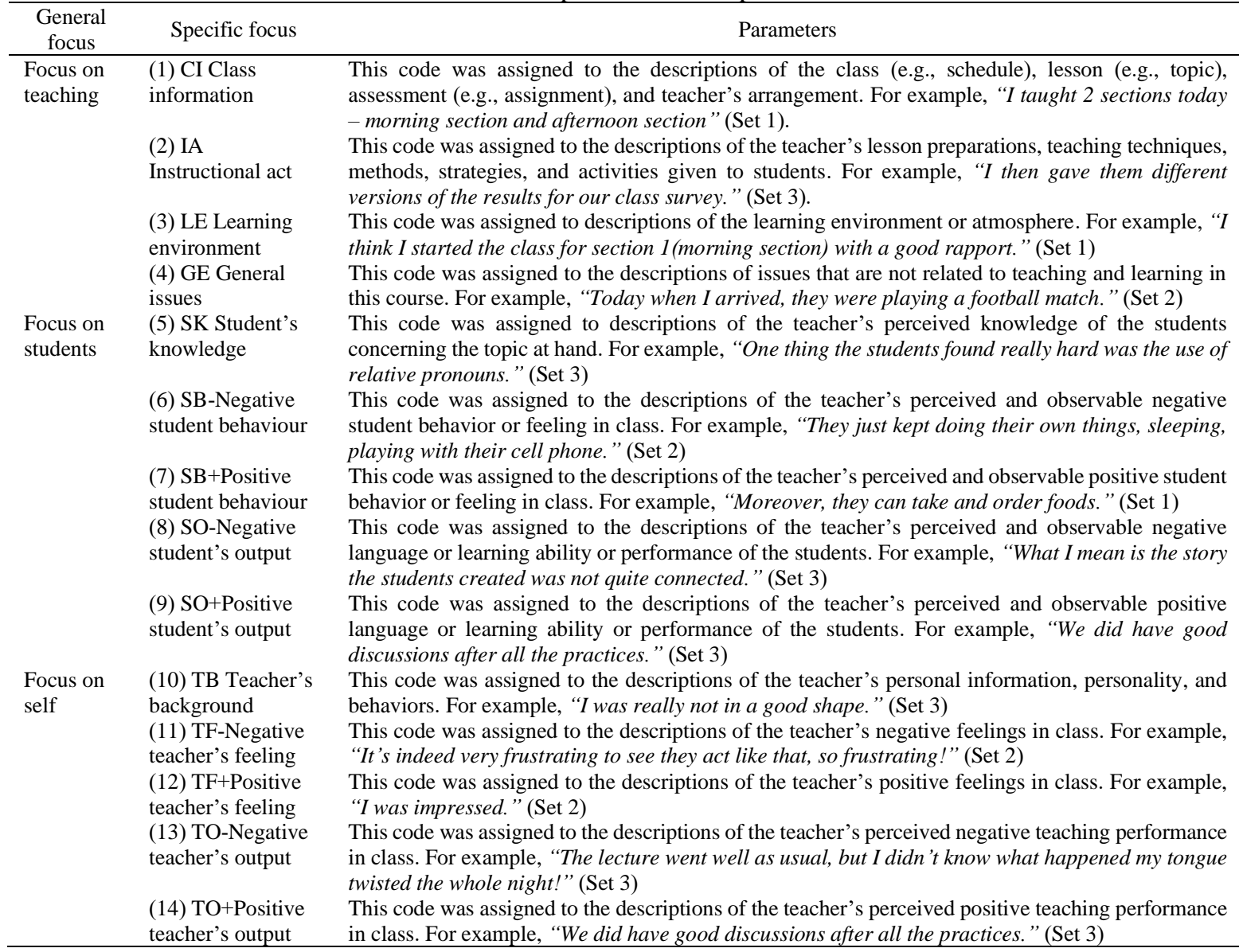

Table 2. Reflective codes and parameters

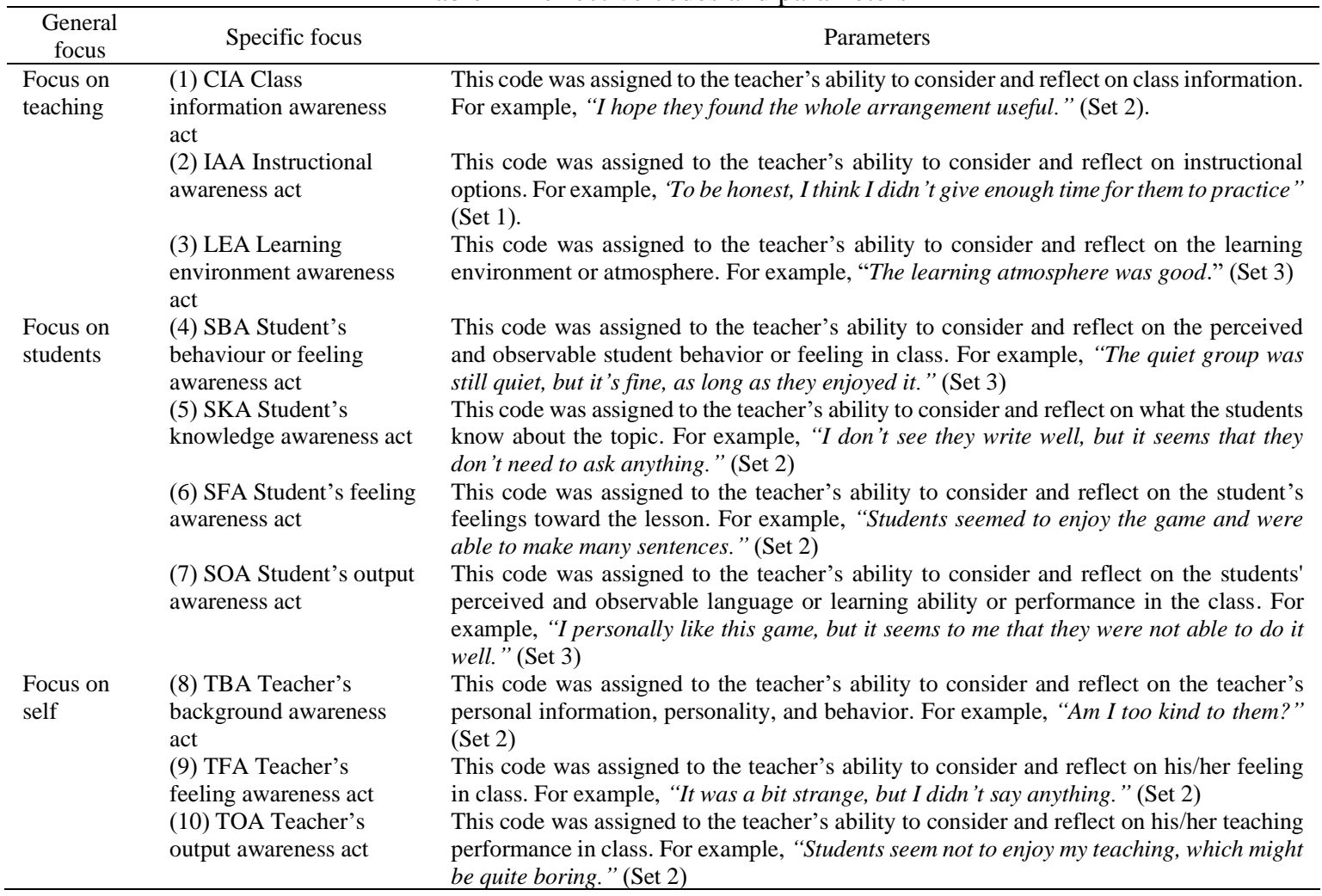

Int J Eval \& Res Educ, Vol. 10, No. 2, June 2021: 668 - 675 
Table 3 provides notable findings with regard to reflective acts novice teachers wrote in their writings. Set 1 shows that the teacher frequently reflects on the instructional awareness act. This means that the novice teacher focused on considering options on her lesson preparations, teaching techniques, methods, strategies, and activities given to students. In Set 2, the novice teacher is fixated on student's behaviours in class. It seemed that the teacher perceived and observed several events where students have behavior or feeling in class. Unlike in Set 2, the teacher in Set 3 provided descriptions of her lesson preparations, teaching techniques, methods, strategies, and activities given to her students.

Based on percentage across data sets, the highest reflective code is the Instructional awareness act in data set 1 . Other notable reflective codes which have at least 15 percent include Instructional act (data sets 1 , 2, and 3), Negative student behaviour (data set 2), Class information (data set 3), and Student behaviour awareness act (data set 2).

Table 3. Frequency and percentage of occurrences in all data sets

\begin{tabular}{|c|c|c|c|c|c|c|c|}
\hline \multirow{2}{*}{ General codes } & \multirow{2}{*}{ Specific codes } & \multicolumn{2}{|c|}{ Set 1} & \multicolumn{2}{|c|}{ Set 2} & \multicolumn{2}{|c|}{ Set 3} \\
\hline & & Frequency & Percentage & Frequency & Percentage & Frequency & Percentage \\
\hline \multirow[t]{7}{*}{ Focus on teaching } & CI & 26 & 13.0 & 47 & 13.0 & 110 & 18.00 \\
\hline & CIA & 1 & 0.50 & 5 & 1.40 & 23 & 3.00 \\
\hline & IA & 57 & 28.0 & 57 & 16.05 & 145 & 23.00 \\
\hline & IAA & 74 & 36.0 & 13 & 3.66 & 57 & 9.00 \\
\hline & LE & 1 & 0.50 & - & - & 2 & 0.33 \\
\hline & LEA & - & - & - & - & 2 & 0.33 \\
\hline & GE & - & - & 20 & 5.63 & 29 & 4.74 \\
\hline \multirow[t]{8}{*}{ Focus on students } & SK & - & - & 1 & 0.28 & 1 & 0.16 \\
\hline & SKA & - & - & 2 & 0.56 & - & - \\
\hline & SB- & 2 & 1.00 & 72 & 20.28 & 18 & 2.95 \\
\hline & $\mathrm{SB}+$ & - & - & - & - & 59 & 9.65 \\
\hline & SBA & 6 & 2.96 & 53 & 15.00 & 24 & 3.93 \\
\hline & SO- & 5 & 2.46 & - & - & 4 & 0.65 \\
\hline & $\mathrm{SO}+$ & 7 & 3.45 & 8 & 2.25 & 39 & 6.38 \\
\hline & SOA & - & - & 7 & 1.97 & 5 & 0.82 \\
\hline \multirow[t]{8}{*}{ Focus on self } & $\mathrm{TB}$ & - & - & 15 & 4.23 & 11 & 1.80 \\
\hline & TBA & - & - & - & - & 4 & 0.65 \\
\hline & TF- & 3 & 1.48 & 7 & 1.97 & 15 & 2.45 \\
\hline & $\mathrm{TF}+$ & 2 & 1.00 & 13 & 3.66 & 32 & 5.24 \\
\hline & TFA & - & - & 7 & 1.97 & 8 & 1.30 \\
\hline & TO- & 5 & 2.46 & - & - & 5 & 0.82 \\
\hline & $\mathrm{TO}+$ & 9 & 4.43 & 1 & 0.28 & 1 & 0.16 \\
\hline & TOA & - & - & - & - & 7 & 1.10 \\
\hline \multicolumn{2}{|c|}{ TOTAL } & 203 & 100.00 & 355 & 100.00 & 611 & 100.00 \\
\hline
\end{tabular}

\section{DISCUSSION}

It is important to highlight the typology revealed in this study to understand novice teachers' reflective practices in the EFL context. Findings reveal interesting codes on what novice teachers in Thailand reflect on their classes, such as class information, learning environment, student's behavior, knowledge, feelings, and output as well teacher's background, feelings, and output. Similar to previous studies [5], [24], [26]-[29], levels of reflective writings do exist among novice teachers in the Thai university context [20], [21]. In this study, a more comprehensive typology was deduced, two general codes-descriptive codes, which refer to the description of a specific event in the classroom, and reflective codes, which are acts in the classroom where the teacher considered an option and reflected on it. These codes elicited may have been the result of free reflective writing. The volunteer participants were asked to write on their own without any structure given. Also, we deduced three sub-codes, including focus on teaching, students, and self.

With regard to the specific focus of their reflective writings, in data set 1 , the Instructional awareness act gained the highest percentage among all codes. Data set 2 highlighted Negative student's behavior. In data set 3 , the Instructional act had the frequency of all the codes. Across data sets, the Instructional act gained the highest percentage.

In all three data sets, the instructional act generally gained the highest percentages, indicating that the two novice teachers focused more on their teaching regardless of their backgrounds. How they delivered the lesson as well as what worked and what did not in the classroom were some of their main concerns. This is especially obvious in data set 1 , where Bee frequently reflected on her lesson preparations and teaching techniques or activities used during the class, comprising more than $60 \%$ of her journals. For example, Bee detailed what she did in her diary: "After that, I decided to teach students how to ask and answer about food experiences: focusing on present perfect (Have/has+V3) to talk about experiences." and evaluated her teaching: "I think my teaching was okay, but not perfect; still have rooms to be improved." In the first few

Exploring the reflective typology of novice EFL teachers in a Thai university (Thidaporn Jumpakate) 
years of teaching, novice teachers might have many trials and errors when planning the lessons, trying to look for the most suitable strategies or methods to facilitate their teaching. Reflections on such instructional acts may help them improve and refine their lessons in the future, enhancing their personal development as a teacher.

Comparatively, Fern showed more concern for students in her reflections, particularly noticeable in her undergraduate course (data set 2). In that data set, Fern described and reflected on many of her students' negative behaviors or feelings, comprising about $35 \%$ of her diary records. For example, she shared in her second day of teaching that "The only things they like were to sleep, to use their cell phone, and to leave as soon as possible." Instead of negative behaviors, she highlighted more of her students' positive sides, including both behaviors and outputs, in her graduate course (data set 3 ). She mentioned quite a number of times talking about how cooperative her students were and said that "They were all very positive and seemed to be very happy with everything." She also appreciated the effort of her students a lot, e.g., "They were able to give good comments, which made me happy." This may suggest that Fern enjoyed more the relationship and rapport she built with students in her graduate class than in the undergraduate course. Bee, however, recorded a lot less about her students in her journals. Such an obvious difference may indicate that with the same cultural background, local novice teachers may be more used to their students' behaviors, making it easier for them to accept how their students respond. On the contrary, Fern might take students' behaviors and reactions more personally as a foreign teacher. Being an alien in a country, foreign novice teachers may be relatively more affected by their learners' behaviors or responses due to their cultural differences.

As regards the focus on self, Fern again reflected relatively more than Bee. As a foreigner, Fern might easily relate her teaching with her background and feelings. When reflecting on her students' negative behaviors in the undergraduate class (data set 2), Fern wondered if there would be something related to her personality, e.g., "I don't understand why ... am I really so scary?" While she also showed high awareness of what she did in teaching (i.e., instructional acts), her being a foreign teacher (i.e., teacher's background) seemed to play a role in her reflections. On the other hand, Fern talked more about her feelings in her diaries, which might induce some affective influence in her teaching experience. For instance, Fern mentioned in her journals (data set 3) near the end of the semester that "I'm content as I really have done very best to improve my teaching." and "We had good sharing and discussion and at the end, I thanked them all." The current study shows that considering such reflections for personal development is more recognizable in foreign novice teachers. That said, however, Bee mentioned a bit more about her positive outputs that Fern in her reflections, e.g., "As for my strengths, I think I can cover all contents and managed time well" and "Eventually, all progresses of teaching passed smoothly and flowing." The results suggest that while some novice teachers may show more concern for their performance during the class, others may associate their personality, behaviors, and feelings more with their teaching.

\section{CONCLUSION}

This article reported a comprehensive list of reflective themes from qualitative analysis of three data sets as part of the novice teachers' aim to improve their teaching. Findings reveal two codes-descriptive and specific. There are three general focuses, including teaching, students, and self. At least 14 and 10 specific focuses were elicited, such as class information, instructional act, learning environment, general issues, students' knowledge, negative student behavior, positive student behavior, negative student's output, positive student's output, teacher's background, negative teacher's feeling, positive teacher's feeling, negative teacher's output, positive teacher' s output, class information awareness act, instructional awareness act, learning environment awareness act, student's behavior or feeling awareness act, student's knowledge awareness act, student's feeling awareness act, student's output awareness act, teacher's background awareness act, teacher's feeling awareness act, teacher's output awareness act.

In the present study, a number of limitations are noted. First, there were only three data sets from two teachers, and the context was limited to one university. Further studies may need to consider a larger number of participants from varied contexts to explore if differences or similarities occur. The analysis was also limited to the emerging codes of the data. Analyzing codes based on time frames may show a more complex reflection of teaching events in the classroom.

\section{REFERENCES}

[1] S.K. Clark, "The plight of the novice teacher," The Clearing House: A Journal of Educational Strategies, Issues and Ideas, vol. 85, no. 5, pp. 197-200, 2012.

[2] H. A. Lawson, "Beyond the new conception of teacher induction," Journal of Teacher Education, vol. 43, no. 3, pp. 163-172, 1992. 
[3] G.E. Hall, "Induction: The missing link," Journal of Teacher Education, vol. 33, no. 3, pp. 53-55, 1982.

[4] S. Feiman-Nemser, "Helping novices learn to teach: Lessons from an exemplary support teacher," Journal of Teacher Education, vol. 52, no. 1, pp. 17-30, 2001.

[5] K. Kim and G. Roth, "Novice teachers and their acquisition of work-related information," Current Issues in Education, vol. 14, no. 1, pp. 1-27, 2011.

[6] J. Burton, P. Quirke, C.L. Reichmann, and J.K. Peyne, Reflective writing: A way to lifelong teacher learning. TESLEG Publications, 2009.

[7] K.F. Osterman and R.B. Kottkamp, Reflective practice for educator. Thousand Oaks, CA: Corwin Press, 2004.

[8] A. Yesilbursa, "A reflective typology emerging from the collaborative reflections of three English language teacher trainers," Education and Science, vol. 36, no.162, pp. 103-111, 2011.

[9] S. Kerka, "Journal writing as an adult learning tool. Practice Application Brief no. 22," ERIC Clearinghouse on Adult, Career, and Vocational Education, 2002.

[10] J.C. Richards, "Second language teacher education today," RELC Journal, vol. 39, no. 2, pp. 158-177, 2008.

[11] N.Y. Kwon and C.H. Orrill, "Understanding a teacher's reflections: A case study of a middle school mathematics teacher," School Science and Mathematics, vol. 107, no.6, pp. 246-257, 2007.

[12] X. Lin, "Reflective adaptation of a technology artifact: A case study of classroom change," Change and Instruction, vol. 19 , no. 4 , pp. $395-440,2001$

[13] M.J. Nathan and E.J. Knuth, "A study of whole classroom mathematical discourse and teacher change," Cognition and Instruction, vol 21, no. 2, pp. 175-207, 2003

[14] S.G. Paris and P. Winograd, The role of self-regulated learning in contextual teaching: Principles and practices for teacher preparation. Columbus, OH: ERIC, 2001.

[15] Z. Arsal, "The Effects of Diaries on Self-Regulation Strategies of Preservice Science Teachers," International Journal of Environmental and Science Education, vol. 5, no. 1, pp. 85-103, 2010.

[16] J. McDonough, "A teacher looks at teachers' diaries,” ELT Journal, vol. 48, no. 1, pp. 57-65, 1994

[17] S. Hidayati, "Exploring novice EAP teacher's self-reflection as a platform for professional development," Indonesian Journal of Applied Linguistics, vol. 8, no. 2, pp. 441-451, 2018.

[18] C. Numrich, "On becoming a language teacher: Insights from diary studies," Tesol Quarterly, vol. 30, no. 1, pp. 131-153, 1996.

[19] T. S. Farrell, "Teacher self-awareness through journal writing," Reflective Practice, vol. 14, no. 4, pp. 465-471, 2013.

[20] S. Wichadee, "Professional development: A path to success for EFL teachers," Contemporary Issues in Education Research (CIER), vol. 4, no. 5, pp. 13-22, 2011.

[21] N. T. T. Loan, "Reflective teaching in an EFL writing instruction course for Thai pre-service teachers," Journal of Asia TEFL, vol. 16, no. 2, p. 561, 2019.

[22] A. Suknaisith, S. Wongwanich, and C. Piromsombat, "Development of teacher performance in educational measurements and evaluation through self-monitoring strategies," Procedia-Social and Behavioral Sciences, vol. 116, no. 1, pp. 1683-1688, 2014.

[23] S. Wongwanich, S. Sakolrak, and C. Piromsombat, "Needs for Thai teachers to become a reflective teacher: Mixed methods needs assessment research," Procedia-Social and Behavioral Sciences, vol. 116, pp. 1645-1650, 2014.

[24] E. Cohen-Sayag and D. Fischl, "Reflective writing in pre-service teachers' teaching: What does it promote?" Australian Journal of Teacher Education, vol. 37, no. 10, pp. 20-36, 2012.

[25] D.A. Schon, The reflective practitioner: How professional think in action. Aldershot: Ashgate, 1991.

[26] T.S. Farrell, Reflective language teaching: From research to practice. London: Continuum, 2007.

[27] M. C. Pennington, "The teacher change cycle," Tesol Quarterly, vol. 29, no. 4, pp. 705-731, 1995.

[28] S. Hall, "Forms of reflective teaching practice in higher education," In R. Pospisil and L. Willcoxson, Eds., Learning Through Teaching. Proceedings of the 6th Annual Teaching Learning Forum, Murdoch University, 1997, p124-131.

[29] C. Stanley, “A framework for teacher reflectivity,” TESOL Quarterly, vol. 32, no. 3, pp. 584-591, 1998.

[30] J. K. Jay and K. L. Johnson, "Capturing complexity: A typology of reflective practice for teacher education," Teaching and teacher education, vol. 18, no. 1, pp. 73-85, 2002.

[31] M. K. Kim, "Pre-service teachers' reflective journal writing on practicum: Focus of reflection and perceptions," Modern English Education, vol. 19, no. 2, pp. 30-41, 2018.

[32] B. Glaser and A.L. Strauss, The Discovery of Grounded Theory: Strategies for Qualitative Research. Aldine, Chicago, IL, 1967.

[33] K. Charmanz and L.L. Belgrave, "Grounded theory," in The Blackwell encyclopedia of sociology. John Wiley \& Sons, Ltd. 2007.

[34] W. Carr and S. Kemmis, Becoming Critical: Education. Knowledge and Action Research. London: Falmer, 1986.

[35] E.A. Davis, "Prompting middle school science students for productive reflection: Generic and directed prompts," The Journal of Learning Sciences, vol. 12, no. 1, pp. 91-142, 2003.

[36] E.A. Davis, "Characterizing productive reflection among pre-service elementary teachers: Seeing what matter," Teacher and Teaching Education, vol. 22, no. 3, pp. 281-301, 2006. 